\title{
TOWARDS A CLOSED STEEL ECO-CYCLE - CONJOINT ANALYSIS AS A DECISION TOOL
}

\author{
Stina Alriksson \\ Tomas Öberg \\ University of Kalmar, Sweden
}

\begin{abstract}
The Swedish steel industry has over the past 20 years made substantial efforts to promote energy efficiency and environment protection. However, the dominant part of these investments has been directed to the individual production sites, most of which today have 'solved' their own acute environmental problems. The focus has therefore switched to the properties and performance of the steel products where the evaluation of environmental performance is a complex task that often requires simultaneous consideration of many different attributes.

Conjoint analysis is commonly used in marketing research, to evaluate how consumers appreciate specific attributes in products. It has also been widely used in health care, traffic planning and quality management. Conjoint analysis has also been applied to environmental issues such as energy, recreation, environmental valuation, ecosystem management, consumer preferences to products, public preferences to industrial projects, waste management, and environmental policy development. This previous research has shown that the method is well suited for evaluating environmental issues.
\end{abstract}

Here we briefly present the methodology and review some papers on environmental applications. It is our intention to use this approach as a tool to integrate environmental considerations into both process and product development within the steel industry.

\section{KEYWORDS}

Steel ecocycle; Conjoint analysis; Experimental design; Environment values

\section{INTRODUCTION}

Mining of iron ore and the production of steel has been one of the most important trades in Sweden during history. Today its contribution to the total Swedish export value is $6.6 \%$ (iron and steel), or $54 \%$ if all goods and products made out of steel are included in the sum (cars, industrial machinery, manufactures of metals, instruments, parts etc.) [1].

The Swedish steel industry has over the past 20 years made substantial efforts to promote energy efficiency and environment protection. However, the dominant part of these investments has been 
directed to the individual production sites, most of which today have 'solved' their own acute environmental problems. The focus has therefore switched to the properties and performance of the steel products. A new challenge for the steel industry is to find out to what extent it can actively contribute to an evolution towards a low-energy, low specific $\mathrm{CO}_{2}$, low-waste and resource-efficient society. Thus a research programme concerning the sustainability of the steel industry as a whole has been commenced - "Towards a Closed Steel Ecocycle".

This interdisciplinary programme aim to increase the technical level of competence and improve the production methods to accomplish a more sustainable and eco-efficient steel industry. The research programme is funded jointly by the Foundation for Strategic Environmental Research (MISTRA) and the industry. The programme consists of six projects, all contributing to a closed steel ecocycle, Figure 1.

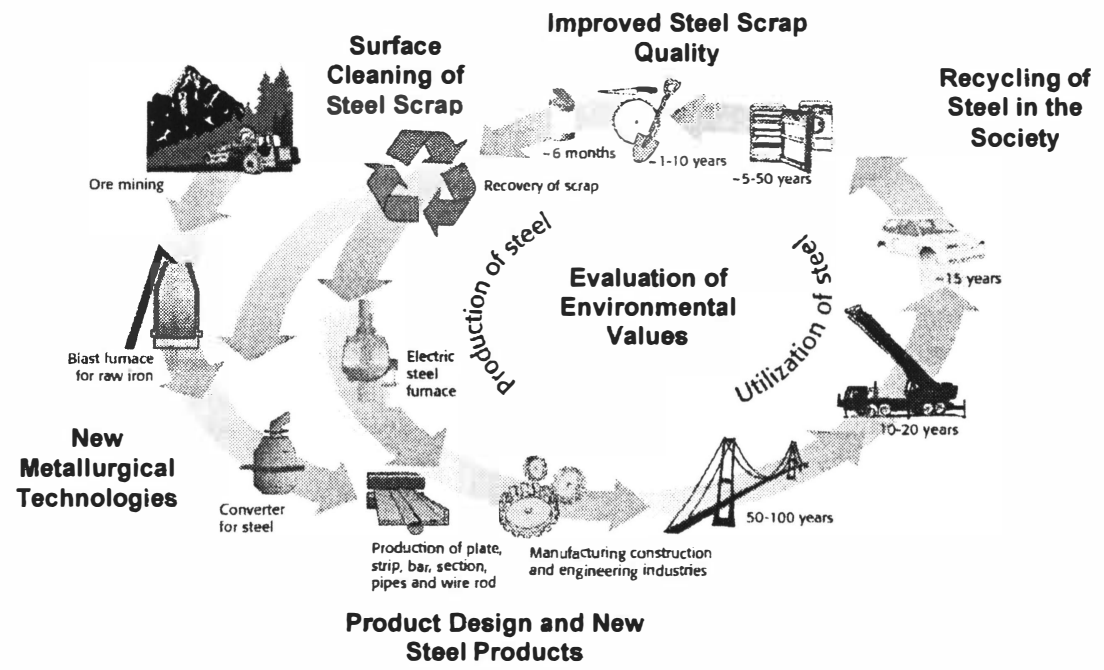

Figure 1. The programme "Towards a closed steel ecocycle" and its six projects [2].

The six projects that can be divided into three subprograms (project clusters):

\section{Recycling}

Improved steel scrap quality is a project that will investigate and develop analytical methods and sorting technology in the shredder plants to improve the quality control of steel scrap.

Surface cleaning of steel scrap. In this project methods for simultaneous preheating and surface cleaning of scrap will be developed for further use in the steel foundry sector. 


\author{
Kalmar ECO-TECH '05 and \\ The Second Baltic Symposium on Environmental Chemistry \\ KALMAR, SWEDEN, November 28-30, 2005
}

New metallurgical technologies is a project aiming to investigate new slag systems and the potential for increased retention of metal valuables in the steel cycle. This will involve novel processes for slag treatment and metallurgical refining during steel-making.

\title{
Economising
}

Product design and new steel products. This project will develop design methods and systematics to minimise the environmental impact from steel products, together with an improvement of production and properties of the steel products.

\section{Relevance studies}

Recycling of steel in the society. The project will analyse the influence of economical and technical variables on the degree and appearance of the recycling of steel. Historical figures will be used to create a model that will be used for forecasting and analysis of possible future developments.

Evaluation of environmental values will provide LCC/LCA support for selected projects, assessment methodology and models as well as decision support tools. One part of the project will develop methodology and models for life-cycle environmental and cost assessments. Another part will develop methodology for evaluating and integrating preferences from various groups of stakeholders into the environmental decision-making process.

The scope of our paper is the second part of the project Evaluation of environmental values. We will briefly describe the research methodology for the subproject Conjoint analysis as a decision tool for evaluation of environmental performance and review some papers on environmental applications of this method.

\section{METHODS}

The evaluation of environmental performance and the choices between altemative solutions is a complex process. Different indexes and scaling systems have been developed to assist the decision-maker, but such approaches often suffer from the fact that the respondents have substantial difficulty in correctly separating and describing/scaling their preferences towards isolated attributes, e.g. toxicity, energy consumption and cost.

\subsection{Conjoint analysis}

Conjoint analysis is a commonly used technique in marketing research, to evaluate how consumers appreciate specific attributes in various products. It has also been widely used in health care, traffic planning and quality management. Green and Srinivasan defined conjoint analysis in 1990 as: " $\ldots$ any decompositional method that estimates the structure of a consumers preferences (i.e. estimates preference parameters such as part-worths, importance weights, ideal points) given his or her overall evaluations of a set of altematives that are prespecified in terms of levels of different attributes" [3]. Since conjoint analysis can be used to reveal the preference structure towards a product or situation, the method is especially suitable for valuing environmental issues [4].

In a conjoint analysis study a respondent is asked to value different altematives or attributes in a hypothetical situation. The researcher is thereby allowed to evaluate the relative importance of 


\section{Kalmar ECO-TECH '05 and \\ The Second Baltic Symposium on Environmental Chemistry \\ KALMAR, SWEDEN, November 28-30, 2005}

these altematives or attributes. Due to the fact that the researcher constructs the hypothetical situation, on the basis of the attributes she or he wants the respondent to evaluate, the method differs from so called revealed preference methods where the actual behaviour of a person is studied. In the conjoint analysis situation, only the hypothetically constructed situation is studied, i.e. what the respondent states that she or he prefers. Thus, conjoint analysis is called a stated preference method.

Luce and Tukey first described conjoint measurement in 1964 [5]. Since then several related methods have evolved, for example choice modelling, conjoint analysis, contingent valuation etc. Many of these methods are similar in their design although several of them differ in the data they generate [6]. They also differ in response mode (rate/rank/choose), method of analysis and conclusions that can be drawn from the results [7]. Although no intemational standard exists, there are some basic steps that are present in most methods $[3,8,9]$ :

1. Selection of attributes and attribute levels to be tested

2. Selection of data collection method (interview, questionnaire)

3. Selection of data collection design ( $\mathrm{rank} / \mathrm{rate} / \mathrm{choose})$

4. Construction of the stimuli for presentation to the respondents (two-factor evaluation or full profile)

5. Data analysis

Conjoint analysis can be used for a variety of purposes, the most common are: prices sensitivity, product development, product evaluation, developing marketing campaigns, advertising, distribution, controlling, repositioning, competitive analysis and in later years, also environmental evaluation [3,8-11].

\subsection{Experimental planning}

Using statistical experimental design as a basis for the investigation enables the researcher to separate and estimate the main effects of the attributes to the respondent's rating/ranking/choice, without risking confounding with interactions.

There are a number of different experimental designs to choose from. The full factorial design uses all combinations of attributes and levels. When using this design the researcher can detect all main effects of each attribute as well as the mean effect and the interactions between the attributes [12-13].

However, if the attributes and levels are extensive, then the all-combination factorial designs will result in a very large number of combinations. Therefore it is common in conjoint analysis to use fractional factorial designs which bring down the number of tested combinations to a manageable number [6, 14-17].

Plackett-Burman designs are yet another type of screening designs used in conjoint analysis. The Plackett-Burman designs are especially suitable for surveys with a large number of attributes, where the fractional factorial design fails to cover all the data [18]. 
Kalmar ECO-TECH '05 and

The Second Baltic Symposium on Environmental Chemistry

KALMAR, SWEDEN, November 28-30, 2005

\subsection{Data analysis}

There are several ways of analyse the collected data, but the choice of method is dependent on the selected model and other decisions made earlier in the conjoint process [9].

Some of the methods used in the reviewed papers are listed below:

- Cluster analysis

- Multinomial logit model [19-20]

- Multiple linear regression [21]

- Binary logistic regression analysis [15]

- Analysis of variance (ANOVA) [15,17]

There is one interesting method that has not yet been evaluated to its full extent; namely bilinear regression methods. Gustafsson proposed the use of partial least squares regression (PLSR) [22]. PLSR is based on a linear transformation of the original data to a limited number of orthogonal factors, attempting to maximize the covariance between the attributes and the stated preferences. Multivariate calibration using PLSR is reviewed by Martens and Næs [23]. Results from a PLSR2-analysis can be efficiently communicated with different graphs and here we see an opportunity for further method development. Another advantage is that it is possible to evaluate the preferences, not only as an aggregate measure for the whole group of participants, but also individually for each participating respondent.

\subsection{Literature review}

An introductory literature review has been conducted through bibliographic database searches of Science Citation Index Expanded (SCI Expanded) and citation lists in identified articles.

\section{RESULTS}

Conjoint analysis (together with related methods) is a relatively new approach for evaluating environmental values. It was not until the mid 90's that the method was first used in a wider concept. Since then conjoint analysis has been applied to several environmental issues such as energy, recreation, environmental valuation, ecosystem management, consumer preferences to environmentally certified products, public preferences to industrial projects and environmental policy development. In Table 1 we have collected some of the conjoint analyses made over the last decade. 
Kalmar ECO-TECH '05 and

The Second Baltic Symposium on Environmental Chemistry

KALMAR, SWEDEN, November 28-30, 2005

Table 1, Environmental applications on conjoint analysis

\begin{tabular}{lll}
\hline Field & Application & Reference \\
\hline Energy & Environmental impact of wind farms & {$[14]$} \\
& Environmental, health, and employment effects of energy & {$[24]$} \\
& programs & \\
& Household preferences for energy-saving measures & {$[17]$} \\
& Willingness to pay for green electricity & {$[25]$} \\
\hline Recreation & Indicators for recreation & {$[26]$} \\
\hline Agriculture & Farmers' perception of unsprayed crop edges & {$[16]$} \\
& Agricultural environmental benefits and costs & {$[27]$} \\
\hline Ecosystem & Deer hunting and landscape change & {$[19]$} \\
management & Value ecosystem change & {$[4]$} \\
& Forest management & {$[28]$} \\
& Tropical rainforest preservation. & {$[29]$} \\
& Ecosystem management & {$[30]$} \\
& Change in river quality on the tourism value of Kruger & {$[21]$} \\
& National Park: & \\
\hline Environmental & Environmental valuation & {$[6,110-11,31-$} \\
evaluation & & $32]$ \\
& Valuing wetland attributes & {$[33]$} \\
& Valuing watershed quality improvements & {$[34]$} \\
& Valuing the benefits of environmentally sensitive areas. & {$[35]$} \\
\hline Waste management & Preferences within the composting industry & {$[36]$} \\
\hline Products & The impact of environmental certification on preferences & {$[15]$} \\
& for wood fumiture and wood products & {$[37]$} \\
& Design for the environment & {$[38]$} \\
& Clean-fuel vehicles & {$[20]$} \\
& Integration of environmental management and product & {$[39]$} \\
\hline design & \\
\hline
\end{tabular}

Traditionally, conjoint analysis has been used in marketing, and an important feature for a market researcher is how much money a consumer is willing to pay for a specific attribute of a product. This way of thinking has been applied also in ecological economics and used in a wide range of conjoint analysis on environmental issues. Farber and Griner estimated the value of improved water quality [34]. Rolfe et al. completed a survey where conservation of rainforest was studied. In this study environmental attributes were mixed with socio-economic attributes resulting in a survey which demanded the respondents to take ethical considerations along with environmental [29]. The authors showed that the conjoint method very well handles this mixture of socioeconomic and environmental attributes to the altematives.

Conjoint analysis can also be used to facilitate the planning of new projects. Carlsson et al. evaluated some attributes in a planned wetland [33]. The attributes investigated were surrounding 


\author{
Kalmar ECO-TECH '05 and \\ The Second Baltic Symposium on Environmental Chemistry \\ KALMAR, SWEDEN, November 28-30, 2005
}

vegetation, biodiversity, fish, fenced waterline, crayfish and walking facilities. The authors found that meadow land, fenced waterline and crayfish were understood to decrease social welfare, while biodiversity and walking facilities were given the largest values for "Willingness To Pay".

Portinga et al. studied the preference for different types of energy saving measures in households [17]. Energy-saving strategies (technical improvement, different use of products and shifts in consumption), domain of saving (home or transport) and the amount of energy savings (small or large) were investigated. It was found that saving energy at home was more acceptable than transport measures, and technical improvements were more acceptable than behavioural measures. Interestingly, there was almost no difference in the household's preference to whether the energy-savings were small or large.

There have been several conjoint analyses made, where a specific attribute for a product was investigated. In 2004 Anderson and Hansen studied the impact of environmental certification on preferences for a wood $\mathrm{CD}$ rack [15]. Although the respondents were not representative for the general population, the results showed that a small part (approximately $20 \%$ ) of the respondents rated environmental certification as the most important feature of the $\mathrm{CD}$ rack. Within this group the respondents were willing to pay extra for the certificate. Among the other respondents however, price was the most important factor, followed by adjustability of the shelves. The results of the study indicate that the large majority of consumers are not willing to pay extra for environmental certified wood in fumiture.

Chen made a similar conclusion when a model was constructed to consider the interactions between consumers, policy makers (govemment) and producers [28]. The author demonstrated that green product development is an expression with different meanings to different stakeholders. For example, producers, consumers and the government may have diffierent views on the "greenness" of a product as well as on its actual benefit to the environment. In the model, conjoint analysis is used to model the consumers purchase behaviour. The author finds that "green product development and stricter environmental standards might not necessarily benefit the environment".

Another interesting application of conjoint analysis is due to Probert et al. analysing preferences within the composting industry in Wales [36]. Main groups of stakeholders were asked to evaluate some attributes of compost soil $(\mathrm{pH}$, price, screen size and level of production specification). The authors conclude that the conjoint analysis works well in this situation and that price was the most important attribute of compost utility by the means of contractors and retailers.

For evaluating the quality of recreational areas, Gossen and Langers constructed a hierarchical conjoint analysis [26]. The method can be used when indicators that influence particular decisions are identified in advance. Twenty-seven hypothetical rural areas were constructed and evaluated by 1250 respondents for cycling, walking, swimming, sailing and fishing. The most important quality indicators were found to be tranquillity, accessibility, water quality and nuisance value. 


\author{
Kalmar ECO-TECH '05 and \\ The Second Baltic Symposium on Environmental Chemistry \\ KALMAR, SWEDEN, November 28-30, 2005
}

\title{
4. CONCLUSIONS
}

Conjoint analysis is a method that is well suited for evaluating environmental issues, as shown in several research projects. The possibility for the researcher to model the hypothetical situation and choose what attributes and levels to be studied gives a unique opportunity to address the specific environmental issues that are of concern within each specific project.

There is a need for the steel industry to have methods and tools to integrate environmental considerations into both process and product development. These tools need to take into consideration the views from several different groups of stakeholders (experts, developers and users). Conjoint analysis seems to be a promising starting point.

We aim to develop such a tool by combining the conjoint analysis with statistical experimental design and multivariate data analysis, using bilinear projection methods and graphical presentation of results as preference maps.

\section{REFERENCES}

[1] Statistics Sweden, 2005. Exports by important SITC commodity groups, January-June 2005, www.scb.se 2005-10-03.

[2] Jemkontoret, 2004. "Steel Eco-cycle, programme plan 2004-2008".

[3] Green, P.E., Srinivasan, V., 1990. Conjoint analysis in marketing: new developments with implications for research and practice. Journal of marketing 54, 3-20.

[4] Farber, S., Griner, B., 2000. "Using conjoint analysis to value ecosystem change", Environmental Science \& Technology 34, 1407-1412.

[5] Luce, R., Tukey, J., 1964. Simultaneous conjoint measurement: a new type of fundamental measurement. Journal of Mathematical Psychology 1, 1-27.

[6] Hanley, N., Mourato, S., Wright, R.E., 2001. Choice modelling approaches: a superior alternative for environmental valuation? Journal of Economic Surveys 15, 435-462.

[7] Louviere, J., 1988. Conjoint analysis modelling of stated preferences. Journal of Transport Economics and Policy 22, 93-120.

[8] Nairn, A., Ede, L., Naudé, P., 2004. Multivariate statistics in industrial marketing management: a practitioner tool kit. Industrial Marketing Management 33, 573-582.

[9] Gustafson, A., Hermann, A., Huber, F. Ed., 2003. Conjoint measurement, methods and applications. Springer-Verlag, Berlin, Germany.

[10] Hanley, N., Wright, R.E., Adamowicz, V., 1998. Using choice experiments to valuate the environment - design issues, current experience and future prospects. Environmental and resource economics $11,413-428$.

[11] Boxall, P., Adamowicz, W., Swait, J., Williams, M., Louviere, J., 1996. A comparison of stated preference methods for environmental valuation. Ecological Economics 18, 243253.

[12] Martens, H., Martens, M., 2001. Multivariate analysis of quality, an introduction. Wiley \& Sons, LTD, Chichester, UK.

[13] Esbensen, K., 2002. Multivariate data analysis - in practice. Camo Process AS, Oslo, Norway. 
[14] Álvarez-Farizo, B., Hanley, N., 2002. Using conjoint analysis to quantify public preferences over the environmental impacts of wind farms. An example from Spain. Energy Policy 30, 107-116.

[15] Anderson, R., Hansen, E., 2004. The impact of environmental certification on preferences for wood furniture: a conjoint analysis approach. Forest Products Journal, 54, 42-50.

[16] van der Meulen, H.A.B., de Snoo, G.R., Wossink, G.A.A., 1996. Farmers' perception of unsprayed crop edges in the Netherlands. Journal of Environmental Management 47, $241-$ 255.

[17] Poortinga, W., Steg, L., Vlek, C., Wiersma, G., 2003. Household preferences for energysaving measures: A conjoint analysis. Journal of Economic Psychology 24, 49-64.

[18] Box, G.E.P., Hunter, W.G., Hunter, J.S., 2005. Statistics for experimenters. Wiley \& Sons, Inc Publication, Hoboken, New Jersey, USA.

[19] Bullock, C., Elston, D., Chalmers, N., 1998. An application of economic choice experiments to a traditional land use-deer hunting and landscape change in the Scottish Highlands. Journal of Environmental Management 52, 335-351.

[20] Ewing, G., Sarigollu, E., 2000. Assessing consumer preferences for clean-fuel vehicles: A discrete choice experiment. Journal of Public Policy \& Marketing 19, 106-118.

[21] Turpie, J., Joubert, A., 2001. Estimating potential impacts of a change in river quality on the tourism value of Kruger National Park: an application of travel cost, contingent and conjoint valuation methods. Water SA 27, 387-398.

[22] Gustafsson, A., 1996. Customer focused product development by conjoint analysis and QFD. Dissertation no 418, Linköping University.

[23] Martens, H., Næs, T., 1989. Multivariate calibration, John Wiley \& Sons, Chichester, UK.

[24] Johnson, F.R., Desvousges, W.H., 1997. Estimating stated preferences with rated-pair data: environmental, health, and employment effects of energy programs. Journal of Environmental Economics and Management 34, 79-99.

[25] Roe, B., Teisl, M., Levy, A., Russell, M., 2001. US consumers' willingness to pay for green electricity. Energy Policy 29, 917-925.

[26] Goossen, M., Langers, F., 2000. Assessing quality of rural areas in the Netherlands: finding the most important indicators for recreation. Landscape and Urban Planning 46, 241-251.

[27] Poe, G., 1999. Maximizing the environmental benefits per dollar expended: an economic interpretation and review of agricultural environmental benefits and costs. Society \& Natural Resources 12, 571-598.

[28] Kangas, J., Kangas, A., 2005. Multiple criteria decision support in forest management - the approach, methods applied, and experiences gained. Forest Ecology and Management 207, 133-143.

[29] Rolfe, J., Bennett., J, Louviere, J., 2000. Choice modelling and its potential application to tropical rainforest preservation. Ecological Economics 35, 289-302.

[30] Stevens, T., Belkner, R., Dennis, D., Kittredge, D., Willis, C., 2000. Comparison of contingent valuation \& conjoint analysis in ecosystem management. Ecological Economics $32,63-74$.

[31] Adamowicz, W., Swait, J., Boxall, P., Louviere, J., Williams, M., 1997. Perceptions versus objective measures of environmental quality in combined revealed and stated preference models of environmental valuation. Journal of Environmental Economics and Management $32,65-84$. 
[32] Blamey, R.K., Bennett, J.W., Louviere, J.J., Morrison, M.D., Rolfe, J.C., 2002. Attribute causality in environmental choice modelling. Environmental \& Resource Economics 23, 167-186.

[33] Carlsson, F., Frykblom, P., Liljenstolpe, C., 2003. Valuing wetland attributes: an application of choice experiments. Ecological Economics 47, 95-103.

[34] Farber, S., Griner, B., 2000. Valuing watershed quality improvements using conjoint analysis. Ecological Economics 34, 63-76.

[35] Garrod, G.D., Willis, K.G., 1999. Methodological issues in valuing the benefits of environmentally sensitive areas. Journal of Rural Studies 15, 111-117.

[36] Probert, E.J., Dawson, G.F., Cockrill, A., 2005. Evaluating preferences within the composting industry in Wales using a conjoint analysis approach. Resources Conservation and Recycling 45, 128-141.

[37] Bigsby, H., Ozanne, L., 2002. The purchase decision: consumers and environmentally certified wood products. Forest Products Journal 52, 100-105.

[38] Chen, C., 2001. Design for the environment: a quality-based model for green product development management science. Management Science 47, 250-263.

[39] Noori, H., Chen, C., 2003. Applying scenario-driven strategy to integrate environmental management and product design. Production and Operations Management 12, 353-368. 